\title{
Conocimiento de los problemas contemporáneos. ¿Es solo cuestión de práctica?
}

\section{Leiva-Brondo, M., Cebolla-Cornejo, J., Peiró, R., Pérez-de-Castro, A. M.}

Departamento de Biotecnología. Universitat Politècnica de València. Valencia. España.

\begin{abstract}
The knowledge of contemporary issues is one of the outcomes recommended by different education systems, including the Spanish. This awareness skill, is basic to assure that the students are able to address societies' issues and it is included among the professional skills that the student must meet at the end of the programme. As an opposite to hard skills, more related to using, designing and applying the knowledge of the programme, the professional skills are more related to the behaviour of the student in his/her professional life. Those skills are harder to teach and practice, but are highly sought-after by company recruiters. Knowledge of contemporary issues is one of those outcome that College and University teachers should include in their subjects and help the students to be more aware of its importance. It is difficult, though, to implement this outcome in the syllabus. En this paper we compare teaching experiences for this outcome following an example-practice scheme in a first year bachelor degree course and in a second year master degree course. En both cases, activities were designed to practice the outcome and they were self- and peer-evaluated. Teachers did not teach directly the outcome. Nevertheless, the students learnt with the activity the importance of being aware of contemporary issues and had feedback of their efforts to improve their skill. Although improvements should be made, the activities helped the student to improve their knowledge of contemporary issues, allowed teachers to assess their students for this outcome and collect evidences of its achievement for accreditation processes. Also, involvement of the student in the assessment process helped them to develop more responsibility in their own learning process.
\end{abstract}

\section{Keywords:}

Outcomes, self and pair-assessemnt, rubrics

\section{Resumen}

La competencia "conocimiento de los problemas contemporáneos" es una de las recomendadas por los distintos sistemas educativos universitarios, incluido el español. Esta competencia es básica para asegurar que el estudiante es capaz de reconocer los problemas actuales que afectan a la sociedad y a su profesión y es una de las denominadas competencias profesionales o transversales que deben adquirir los estudiantes al final de sus estudios. Al contrario que las competencias especificas de la titulación, 
más relacionadas con usar, diseñar y aplicar los conocimientos del programa, las competencias profesionales están más relacionadas con el comportamiento del estudiante en su vida profesional. Estas habilidades son más dificiles de enseñar y practicar, pero son muy valoradas por el sector profesional cuando contrata su personal. El conocimiento de los problemas contemporáneos es una de estas competencias, que los profesores universitarios deben incluir en sus asignaturas y ayudar a los estudiantes a ser conscientes de su importancia. Sin embargo, puede resultar complejo incluir esta competencia en el programa de la asignatura. En este artículo se comparan las actividades de enseñanza-aprendizaje en una asignatura de primer curso de grado y una asignatura de segundo curso de máster. En ambos casos, se diseñaron actividades para practicar esta competencia y fueron evaluadas por los propios alumnos y por sus pares, así como por los profesores. Los profesores no enseñaron de forma explícita la competencia, pero los estudiantes al realizar la actividad se dieron cuenta de la importancia de la misma y recibieron información para trabajarla. Aunque es necesario realizar mejoras, las actividades favorecieron el conocimiento de los problemas contemporáneos de los alumnos, permitieron a los profesores evaluar a los alumnos en esta competencia y recoger evidencias para los procesos de acreditación. Los alumnos al estar involucrados en su proceso de evaluación lograron más responsabilidad en su propio proceso de aprendizaje.

Palabras clave: Competencias, auto-evaluación y evaluación por pares, rúbricas

\section{Introducción}

La formación en competencias es un objetivo de nuestra socided actual (Tremblay et al. 2013; Symonds et al. 2011). Debido a ello, la educación superior universitaria ha cambiado de un sistema basado en la transmisión de conocimientos a un sistema basado en la educación en competencias (Outcome based education; (Landrum 2015)). El objetivo último es que los estudiantes al finalizar sus estudios dominen una serie de competencias que les preparen para su futuro laboral (Sheffield 2014). Sin embargo, la lista de competencias que ha de lograr el alumno no está consensuada y varía según los estudios, universidades, países y agencias de acreditación. Por otro lado, esa lista de competencias es cambiante con el tiempo, como demuestra la reciente propuesta de actualización que ha realizado la agencia americana de acreditación ABET (ABET 2016). En la Universitat Politècnica de València se ha definido una lista de 13 competencias genéricas a todos los títulos de la universidad (Tabla 1) (UPV 2016). Estas competencias pretenden aunar las normativas y directrices más importantes a nivel nacional e internacional, así como unificar esfuerzos al tener todos los programas objetivos comunes.

(cc) EY-NC-ND 2016, Universitat Politècnica de València 
Tabla 1. Competencias establecidas por la Universitat Politècnica de València (UPV).

Título

Descripción

Comprensión e integración
Aplicación pensamiento práctico
Análisis y resolución de problemas
$\begin{aligned} & \text { Innovación, } \\ & \text { emprendimiento }\end{aligned}$

Diseño y proyecto

Trabajo en equipo y liderazgo

Demostrar la comprensión e integración del conocimiento tanto de la propia especialización como en otros contextos más amplios.

Aplicar los conocimientos a la práctica, atendiendo a la información disponible, y estableciendo el proceso a seguir para alcanzar los objetivos con eficacia y eficiencia.

Analizar y resolver problemas de forma efectiva, identificando y definiendo los elementos significativos que lo constituyen.

y Innovar para responder satisfactoriamente y de forma original a las necesidades y demandas personales, organizativas y sociales con actitud emprendedora.

Diseñar, dirigir y evaluar una idea de manera eficaz hasta concretarla en un proyecto.

Trabajar y liderar equipos de forma efectiva para la consecución de objetivos comunes, contribuyendo al desarrollo personal y profesional de los mismos.

Responsabilidad ética y profesional Actuar con responsabilidad ética y profesional ante uno mismo y los demás.

Comunicación efectiva Comunicarse de manera efectiva, tanto de forma oral como escrita, utilizando adecuadamente los recursos necesarios y adaptándose a las características de la situación y la audiencia.

Pensamiento crítico Desarrollar un pensamiento crítico interesándose por los fundamentos en los que se asientan las ideas, acciones y juicios, tanto propios como ajenos.

Conocimiento de los problemas Conocimiento de los problemas contemporáneos. contemporáneos

Aprendizaje permanente

Utilizar el aprendizaje de manera estratégica, autónoma y flexible, a lo largo de toda la vida, en función del objetivo perseguido.

Planificación y gestión del tiempo Planificar adecuadamente el tiempo disponible y programar las actividades necesarias para alcanzar los objetivos, tanto académicosprofesionales como personales.

Instrumental específica Capacidad para utilizar las técnicas, las habilidades $y$ las herramientas actualizadas necesarias para la práctica de la profesión.

Proyecto institucional Incorporación de las competencias transversales en el currículo de los egresados de la UPV," 2015. Disponible en: $<$ http://www.upv.es/entidades/ICE/info/U0702452.pdf $>$ [Consulta: 18 Enero 2016].

(cc) EY-NC-ND 2016, Universitat Politècnica de València

Congreso In-Red (2016) 
$\mathrm{Al}$ contrario que las competencias específicas de la titulación, más relacionadas con usar, diseñar y aplicar los conocimientos del programa, las competencias profesionales están más relacionadas con el comportamiento del estudiante en su vida profesional (Shuman et al. 2005). Estas habilidades son más difíciles de enseñar y practicar, pero son muy valoradas por las compañías cuando contratan su personal. Sin embargo, enseñar a los alumnos estas competencias no es un proceso sencillo, ya que no se limita a la mera transmisión de conocimiento, sino que es necesario que los alumnos practiquen esas enseñanzas y en muchos casos cambien su forma de comportarse o de afrontar nuevas situaciones. Por ello, es necesario cambiar los métodos de enseñanza-aprendizaje para adaptarlos a esta nueva situación. Además, no solo hay que enseñar estas competencias, sino evaluarlas y comprobar que los alumnos las adquieren de forma efectiva, además de obtener evidencias de ello para los procesos de acreditación.

El conocimiento de los problemas contemporáneos es una de las competencias que es difícil de evaluar utilizando métodos tradicionales (Sala et al. 2011). Es una competencia relacionada con los desarrollos recientes en el campo profesional (Balachandran et al. 2008), aunque no existe una definición consenso para la misma (Schwartz y Kranov 2012). Para trabajar esta competencia se pueden utilizar diferentes enfoques (revisados por Shuman et al. 2005), incluyendo el estudio de casos, la discusión de artículos o temas por los estudiantes o el uso de encuestas (Sala et al. 2011; Balachandran et al. 2008; Schwartz y Kranov 2012; Pong et al. 2005). Estos enfoques pueden ser combinados con técnicas de autoevaluación, evaluación por pares y evaluación por parte del profesor, donde se logra la implicación del estudiante en su evaluación y en su aprendizaje (Boud y Falchikov 1989; Dochy et al. 1999). En el presente artículo se analizan y comparan actividades destinadas a evaluar el conocimiento de los problemas contemporáneos en alumnos de primer curso de grado y alumnos de segundo curso de máster.

\section{Objetivos}

El objetivo del presente artículo es comparar los resultados de actividades realizadas para lograr mejorar el conocimiento de los problemas contemporáneos en los alumnos y evaluar su efectividad, planteando posibles opciones de mejora.

\section{Desarrollo de la innovación}

La innovación se ha realizado en dos asignaturas diferentes, pero con profesores comunes y ambas punto de control de la competencia conocimiento de los problemas contemporáneos, de primer curso de grado y segundo curso de máster. Es decir, alumnos que inician su educación universitaria y alumnos que están finalizando sus estudios universitarios.

En el primer caso se trata de la asignatura "Genética General" de primer curso del Grado en Biotecnología de la UPV. Esta asignatura tiene alrededor de 120 alumnos cada año. Se caracteriza por tener alumnos con alta nota de acceso a la universidad y muy motivados por sus estudios y la asignatura en particular. La asignatura consta de 3,5 ECTS de teoría y 2,5

(cc)) BY-NC-ND 2016, Universitat Politècnica de València 
ECTS de prácticas de aula y laboratorio. En el curso de estudio (2015-16) los alumnos fueron divididos en tres grupos, en uno de ellos ( 25 alumnos) se impartieron las clases en inglés y en los otros dos (50 alumnos cada uno) se impartieron las clases en castellano.

En el segundo caso, la asignatura es "Mejora genética del rendimiento en los sistemas agrarios" y se imparte en segundo curso del máster en Mejora Genética Vegetal de la UPV. Los alumnos están muy motivados por el título y proceden de diversas carreras relacionadas con la temática del máster. La asignatura consta de 4 ECTS de teoría y 1 ECTS de prácticas informáticas. En los cursos de estudio (2013-14 y 2014-15) el número de alumnos varió entre 10 y 15 y la docencia fue en castellano.

La actividad en ambos casos consistió en la presentación y discusión de artículos o noticias contemporáneas relacionadas con la asignatura, por ejemplo Blech (2013). Dado el elevado número de alumnos en la asignatura de primer curso, se organizó a los alumnos en grupos de 5-6 personas, siendo 24 el número total de grupos. Además, la presentación se realizó mediante la entrega de un "screencast" grabando su voz con programas gratuitos disponibles en internet como Screencast-o-matic (https://screencast-o-matic.com) y que fue elaborado con la herramienta colaborativa Google Drive (https://www.google.com/intl/es_es/drive/). Se realizó una presentación por grupo. En el caso de la asignatura de segundo curso de master las presentaciones y discusiones de los artículos fueron individuales y se realizaron en el aula. Cada alumno realizó 10 presentaciones. En ambos casos, los alumnos disponían previamente de instrucciones detalladas de cómo realizar la presentación y discusión del artículo, así como las rúbricas que se utilizaban en la evaluación de las presentaciones (Tabla 2). En el caso de la asignatura de primer curso, se evaluó además el trabajo en grupo con una rúbrica adicional (Tabla 3). En ambas asignaturas los alumnos tenían que autoevaluar su presentación y evaluar la presentación de sus compañeros (en el caso de la asignatura de primer curso sólo tres de ellas, mientras que en la asignatura del máster todas las de sus compañeros). Los profesores, por otro lado, evaluaron las presentaciones de todos los alumnos utilizando las mismas rúbricas. Tanto la autoevaluación, la evaluación por pares como la evaluación del profesor se tuvieron en cuenta para la evaluación de la actividad y esta actividad formaba parte de la nota final de la asignatura. La herramienta PoliformaT basada en Sakai fue utilizada para recabar toda la información y enviar los resultados a los alumnos. 

Tabla 2. Rúbrica utilizada en la autoevaluación evaluación por pares y evaluación del profesor de la activida. La rúbrica fue elaborada siguiendo las recomendaciones y ejemplos de la universidad "Papel de las rúbricas en la evaluación de las competencias transversales UPV," 2015. Disponible en: <http://www.upv.es/entidades/ICE/info/U0702453.pdf> [Consulta: 18 Enero 2016].

\begin{tabular}{|c|c|c|c|c|c|}
\hline \multirow[b]{2}{*}{ INDICADORES } & \multicolumn{4}{|c|}{ DESCRIPTORES } & \multirow[b]{2}{*}{$\begin{array}{c}\text { Calificación } \\
\%\end{array}$} \\
\hline & D. No alcanzado & C. En desarrollo & B. Bien /adecuado & A. Excelente/ejemplar & \\
\hline $\begin{array}{l}\text { La exposición está } \\
\text { estructurada de modo } \\
\text { coherente }\end{array}$ & $\begin{array}{l}\text { La exposición evidencia falta de } \\
\text { orden y/o jerarquía en la } \\
\text { presentación de sus ideas }\end{array}$ & $\begin{array}{l}\text { La estructura de la exposición } \\
\text { no facilita su comprensión }\end{array}$ & $\begin{array}{l}\text { La exposición está estructurada } \\
\text { de un modo coherente, que } \\
\text { facilita su comprensión }\end{array}$ & $\begin{array}{l}\text { La exposición resulta } \\
\text { organizada, completa y eficaz }\end{array}$ & 20 \\
\hline $\begin{array}{l}\text { Utiliza el lenguaje con } \\
\text { corrección gramatical: } \\
\text { semántica, sintáctica y } \\
\text { ortográfica }\end{array}$ & $\begin{array}{l}\text { Construye frases sin sentido, } \\
\text { utiliza un vocabulario pobre y/o } \\
\text { comete faltas de ortografia }\end{array}$ & $\begin{array}{l}\text { Comete errores gramaticales } y / o \\
\text { utiliza frases pobremente } \\
\text { estructuradas y/o un vocabulario } \\
\text { impreciso }\end{array}$ & $\begin{array}{l}\text { Utiliza el lenguaje con } \\
\text { corrección semántica, sintáctica } \\
\text { y gramatical }\end{array}$ & $\begin{array}{l}\text { Evidencia un uso rico y preciso } \\
\text { del lenguaje, así como un } \\
\text { vocabulario variado, adecuado y } \\
\text { específico }\end{array}$ & 20 \\
\hline $\begin{array}{l}\text { Explica correctamente, con } \\
\text { sus propias palabras, las } \\
\text { ideas planteadas en un texto, } \\
\text { problema, ejercicio... }\end{array}$ & $\begin{array}{l}\text { No es capaz de exponer las } \\
\text { ideas con un orden }\end{array}$ & $\begin{array}{l}\text { Explica bien algunas ideas, pero } \\
\text { a veces confunde la secuencia } \\
\text { y/o la agrupación de } \\
\text { elementos... }\end{array}$ & $\begin{array}{l}\text { Explica correctamente las ideas, } \\
\text { utilizando recursos lingüísticos } \\
\text { adecuados }\end{array}$ & $\begin{array}{l}\text { Explica las ideas o conceptos y } \\
\text { la importancia o coherencia de } \\
\text { su secuencia, agrupamiento... }\end{array}$ & 20 \\
\hline $\begin{array}{l}\text { Describe el problema y sus } \\
\text { características principales } \\
\text { con un vocabulario } \\
\text { adecuado en distintos } \\
\text { contextos de forma oral o } \\
\text { escrita }\end{array}$ & $\begin{array}{l}\text { No describe el problema o lo } \\
\text { describe de forma insuficiente }\end{array}$ & $\begin{array}{l}\text { Describe el problema } \\
\text { superficialmente sin indicar sus } \\
\text { características principales }\end{array}$ & $\begin{array}{l}\text { Describe el problema con mayor } \\
\text { profundidad e indica algunas } \\
\text { características principales. Todo } \\
\text { ello con un vocabulario } \\
\text { adecuado }\end{array}$ & $\begin{array}{l}\text { Describe el problema con mayor } \\
\text { profundidad e indica muchas } \\
\text { características principales. Todo } \\
\text { ello con un vocabulario } \\
\text { adecuado }\end{array}$ & 40 \\
\hline
\end{tabular}


Tabla 3. Rúbrica utilizada en la autoevaluación evaluación por pares del trabajo en grupo. La rúbrica fue elaborada siguiendo las recomendaciones y ejemplos de la universidad "Papel de las rúbricas en la evaluación de las competencias transversales UPV," 2015. Disponible en: <http://www.upv.es/entidades/ICE/info/U0702453.pdf> [Consulta: 18 Enero 2016].

\begin{tabular}{|c|c|c|c|c|c|}
\hline \multirow[b]{2}{*}{ INDICADORES } & \multicolumn{4}{|c|}{ DESCRIPTORES } & \multirow[b]{2}{*}{$\begin{array}{c}\text { Calificació } \\
\text { n (\%) }\end{array}$} \\
\hline & D. No alcanzado & C. En desarrollo & B. Bien /adecuado & A. Excelente/ejemplar & \\
\hline $\begin{array}{l}\text { Acude y participa } \\
\text { activamente en las } \\
\text { reuniones } \\
\text { del equipo }\end{array}$ & $\begin{array}{l}\text { No acude a las reuniones o } \\
\text { acude con una actitud negativa }\end{array}$ & Acude a las reuniones & $\begin{array}{l}\text { Acude a las reuniones con una } \\
\text { actitud de escucha activa y } \\
\text { participativa }\end{array}$ & $\begin{array}{l}\text { Participa activamente en las } \\
\text { reuniones y fomenta } \\
\text { participación del resto de } \\
\text { miembros del equipo }\end{array}$ & 25 \\
\hline $\begin{array}{l}\text { Participa en la } \\
\text { planificación de objetivos }\end{array}$ & $\begin{array}{l}\text { No se implica en la } \\
\text { planificación }\end{array}$ & $\begin{array}{l}\text { Acepta la planificación } \\
\text { propuesta por los demás }\end{array}$ & $\begin{array}{l}\text { Participa activamente en la } \\
\text { planificación }\end{array}$ & $\begin{array}{l}\text { Lleva la iniciativa en } \\
\text { planificación y fomenta } \\
\text { colaboración }\end{array}$ & 25 \\
\hline $\begin{array}{l}\text { Acepta y cumple los } \\
\text { objetivos del equipo }\end{array}$ & $\begin{array}{l}\text { No cumple con los objetivos } \\
\text { comunes del equipo }\end{array}$ & $\begin{array}{l}\text { Acepta los objetivos comunes } \\
\text { que no entran en conflicto con } \\
\text { sus intereses }\end{array}$ & $\begin{array}{l}\text { Acepta y cumple los objetivos } \\
\text { comunes }\end{array}$ & $\begin{array}{l}\text { Cumple con los objetivos del } \\
\text { equipo y motiva al resto de } \\
\text { integrantes para alcanzarlos }\end{array}$ & 25 \\
\hline $\begin{array}{l}\text { Realiza las tareas que le son } \\
\text { asignadas dentro del equipo } \\
\text { en el plazo fijado }\end{array}$ & No realiza las tareas asignadas & $\begin{array}{l}\text { Realiza las tareas asignadas } \\
\text { parcialmente y/o no siempre } \\
\text { cumple los plazos }\end{array}$ & $\begin{array}{l}\text { Realiza las tareas asignadas } \\
\text { dentro del plazo establecido }\end{array}$ & $\begin{array}{l}\text { Realiza las tareas asignadas con } \\
\text { un alto nivel de calidad, en los } \\
\text { plazos establecidos }\end{array}$ & 25 \\
\hline
\end{tabular}




\section{Resultados}

En ambas asignaturas, los alumnos participaron en la actividad, la elaboraron y la evaluaron siguiendo los criterios descritos. Sin embargo, no todos los alumnos enviaron los resultados de autoevaluación o evaluación por pares, aunque se recabaron datos de más del $90 \%$ de las evaluaciones de los alumnos o las presentaciones. La nota de la actividad fue elevada en ambos casos (Tabla 4). Hay que tener en cuenta que en ambos casos los alumnos están muy implicados en la asignatura y los temas que tratan están muy relacionados con la misma, por lo que su motivación es alta en ambos casos.

Tabla 4. Notas de los distintos apartados evaluados en la asignatura de grado y máster

\begin{tabular}{c|c|c|c|c|c|c|} 
Asignatura & Nota final & $\begin{array}{c}\text { Evaluación } \\
\text { profesor }\end{array}$ & Autoevaluación & $\begin{array}{c}\text { Evaluación } \\
\text { por pares }\end{array}$ & $\begin{array}{c}\text { Valoración } \\
\text { trabajo } \\
\text { compañeros }\end{array}$ & $\begin{array}{c}\text { Autoevaluación } \\
\text { trabajo en } \\
\text { grupo }\end{array}$ \\
\hline Grado & $8,48 \pm 0,03 \mathrm{a}$ & $8,12 \pm 0,06 \mathrm{~b}$ & $8,92 \pm 0,19 \mathrm{~b}$ & $8,79 \pm 0,07 \mathrm{~b}$ & $8,78 \pm 0,07$ & $9,24 \pm 0,10$ \\
\hline Máster & $8,66 \pm 0,05 \mathrm{~b}$ & $7,82 \pm 0,07 \mathrm{a}$ & $7,76 \pm 0,13 \mathrm{a}$ & $8,05 \pm 0,08 \mathrm{a}$ & --- & -- \\
\hline
\end{tabular}

Diferentes letras dentro de una misma columna indicant diferencas significativas (Tukey test, $\mathrm{P}<0.05)$.

Respecto a las notas en los distintos apartados en general las notas de grado son superiores a las de máster. Este hecho podría explicarse debido al menor nivel de exigencia en primer curso o la elevada nota de acceso a la universidad que tienen estos alumnos. El grado en Biotecnología tiene la segunda nota de corte (12,3 sobre 14) más elevada de la universidad y es la tercera de todos los grados en Biotecnología de España. En los apartados de autoevaluación y la evaluación por pares, en la asignatura de grado las notas fueron más elevadas que las observadas en la asignatura de máster. Este hecho podría ser debido a la diferencia de edad de los estudiantes; mientras que en grado los alumnos acaban de entrar en la universidad, en la asignatura de máster, los alumnos están a punto de acabar sus estudios universitarios y tienen más experiencia a la hora de juzgar presentaciones y análisis crítico de los artículos, por lo que suelen ser más exigentes.

En el caso de la asignatura de grado se evaluó el trabajo en grupo de los alumnos, tanto por los propios alumnos como por sus compañeros, observando una mayor nota en la autoevaluación que en la evaluación de sus pares. Esto podría ser debido a una alta percepción de su propio trabajo por parte del alumno o a una precupación sobre como afecta a su nota final esta evaluación.

Las correlaciones entre los ditintos aspecto incluidos en la nota final (Tabla 5) resultaron altamente significativas y con valores medios en casi todos los casos. La autoevaluación es el aspecto que correlaciones más bajas obtuvo o en algún caso no fueron signficativas. En el caso de la asignatura de grado se obtuvieron correlaciones negativas entre la evaluación del profesor y la autoevaluación y la evaluación por pares. Una posible explicación podría ser a que los alumnos con peores notas se valoraran a sí mismos mejor que los alumnos con mejores notas. También parece indicar un criterio distinto a la hora de autoevaluarse que al 
evaluar a los compañeros. Por ello se hace necesario mejorar la explicación de los criterios de evaluación. En todo caso, hay que tener en cuenta que la autoevaluación es una parte de la nota de la actividad y la actividad es un parte de la nota final de la asignatura, por lo que su influencia no es muy grande en el global de la asignatura. De todas formas, aun teniendo en cuenta la distinta aplicación de los criterios, es importante mantener este apartado de la evaluación porque fomenta la implicación del alumnado en su evaluación y aumenta su responsabilidad en su aprendizaje (Boud y Falchikov 1989; Dochy et al. 1999).

Tabla 5. Correlaciones entre los distintos apartados evaluados.

Valores significativos $(* *(\mathrm{P}<0.01) \mathrm{y} * * *(\mathrm{P}<0.001)$.

\begin{tabular}{lcc} 
Asignatura/Apartado & Autoevaluación & $\begin{array}{c}\text { Evaluación por } \\
\text { pares }\end{array}$ \\
\hline $\begin{array}{l}\text { Grado } \\
\text { Evaluación profesor } \\
\text { Autoevaluación }\end{array}$ & $-0,1520$ & $-0,3217 * * *$ \\
& & 0,1388 \\
\hline $\begin{array}{l}\text { Máster } \\
\text { Evaluación profesor } \\
\text { Autoevaluación }\end{array}$ & $0,2866^{* * *}$ & $0,4565^{* * *}$ \\
\hline $\begin{array}{c}\text { Ambas } \\
\text { Evaluación profesor } \\
\text { Autoevaluación }\end{array}$ & $0,2387^{* * *}$ & $0,2215^{* *}$ \\
\hline
\end{tabular}

Se observó una gran dispersión en las notas, aunque dentro de un rango de notas altas (Figura 1). Tanto los alumnos como los profesores utilizaron las mismas rúbricas para realizar la evaluación, pero la interpretación de dichas rúbricas es algo que depende del nivel de exigencia y de la experiencia de evaluación, lo que podría explicar algunas de las diferencias. Un aspecto de mejora para próximos años podría ser entregar a los alumnos presentaciones ya elaborados y calificados lo que podría servir como ejemplo para los alumnos y ayudaría a tener criterios más uniformes.

Entre las dos asignaturas la diferencia principal es el número de alumnos. En la asignatura de primer curso, el número de alumnos es muy elevado y la carga de trabajo mayor, por lo que se optó en hacer las presentaciones "on line" en vez de presenciales, como se hizo en la asignatura de máster. Es cierto que de esta forma se pierde la discusión con los alumnos y la posibilidad que los compañeros planteen dudas, pero dado el tiempo que dispone la asignatura, la opción de presentación presencial resulta inviable. Todas las presentaciones estaban disponibles para todos los alumnos por lo que tenían la opción de visualizarlas todas, no solo las que debían evaluar. Para asegurar que los alumnos han visualizado todas las presentaciones, sería necesario plantear alguna actividad adicional. Como ejemplo, se podrían elaborar cuestionarios que los alumnos tendrían que responder al finalizar la visualización de las presentaciones. 

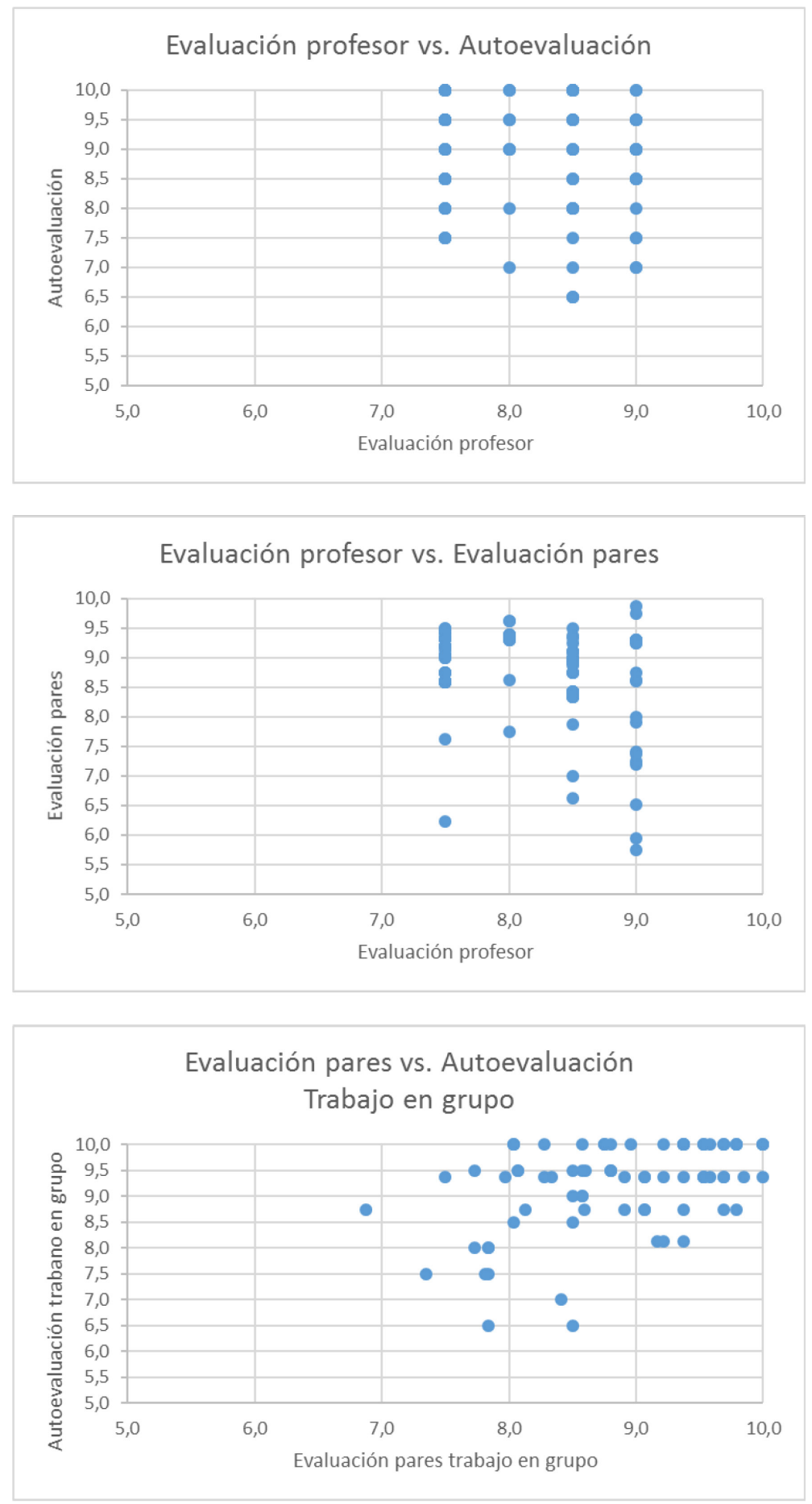

Fig. 1. Relación entre los distintos apartados evaluados en la actividad para la asignatura Genética General. 


\section{Conclusiones}

La evaluación de competencias profesionales, como es el caso de conocimiento de problemas conteporáneos, no está tan desarrollada como la evaluación de competencias específicas (Shuman et al. 2005), pero es un aspecto que demanda mayor interés en la educación universitaria. Esta competencia no pretende que el alumno adquiera un conocimiento específico, si no que se de cuenta de la importancia de estar "al día" de los avances en su campo profesional y los aplique, por lo que es más un cambio de comportamiento o actitud. Los enfoques más utilizados se basan en plantear distintos problemas contemporáneos a los alumnos para que los analicen, bien mediante casos, análisis de artículos o encuestas (Sala et al. 2011; Balachandran et al. 2008; Schwartz y Kranov 2012). En el presente artículo se analizan actividades encaminadas al fortalecimiento de esta competencia en asignaturas de grado y máster. En ambos casos el resultado es satisfactorio y los alumnos realizaron la actividad de forma satisfactoria, incluso en una asignatura con un número elevado de estudiantes, gracias al uso de herramientas telemáticas. Aunque es necesario mejorar el procedimiento y explicar mejor las rúbricas para una valoración más objetiva, la actividad puede ser utilizada en asignaturas con muchos y pocos alumnos para evaluar el nivel de alcance de la competencia, obtener información para procesos de acreditación y fomentar la implicación del alumno en su proceso de aprendizaje.

\section{Agradecimientos}

Los autores agradecen la financiación propocionada por el Vicerrectorado de Estudios, Calidad y Acreditación de la Universitat Politècnica de València mediante la convocatoria de ayudas para Proyectos de Innovación y Mejora Educativa (PIME).

\section{Referencias}

ABET (2016). Accreditation Alerts. http://www.abet.org/. Disponible en: $<$ http://www.abet.org/accreditation/accreditation-criteria/accreditation-alerts/> [Consulta Marzo 31, 2016].

BALACHANDRAN S, CLOUGH J, JINKINS P, KILE J. (2008). "Guidelines for integrating contemporary issues into engineering y technology curricula". En 2008 American Society for Engineering Education (ASEE) North Midwest Section Conference. Platteville, WI.

BLECH, J. (2013). "No todo está en los genes". Investigación y Ciencia, 439:92-94 Disponible en: <http://www.investigacionyciencia.es/files/12923.pdf> [Consulta: Marzo 30, 2016].

BOUD, D. y FALCHIKOV, N. (1989). "Quantitative studies of student self-assessment in higher education: a critical analysis of findings". Higher Education, 18(5), pp.529549. Disponible en: <http://link.springer.com/10.1007/BF00138746> [Consulta: Marzo 30, 2016].

DOCHY, F., SEGERS, M. y SLUIJSMANS, D. (1999). The Use of Self- , Peer and Co - 
assessment in Higher Education : a review,

LANDRUM E. (2013). Teach Like It's 2099. https://thebluereview.org. 2013 . Disponible en: <https://thebluereview.org/teach-like-its-2099/> [Consulta: Marzo 30, 2016].

PONG W, MARZO A, SHAHNASSER H, LIOU S. (2005). "Contemporary Issues in Undergraduate Engineering Education". En Proceedings of the 2005 iNEER (International Network for Engineering Education and Research). Taiwan.

SALA, A.L., SPENDLOVE, T. y RIDDELL, J. (2011). "Assessment of ABET Program Outcome J, "A knowledge of contemporary issues". En 118th ASEE annual conference $y$ exposition. Vancuver, B. C. Canada. Disponible en: $<\mathrm{http} / /$ www.asee.org/public/conferences/1/papers/883/view> [Consulta: Marzo 30, 2016].

SCHWARTZ, J.D. y KRANOV, A.A. (2012). "Introducing contemporary issues to engineering students: A case study module". ASEE Annual Conference and Exposition, Conference Proceedings.

SHEFFIELD, C. (2014). "Skills-Based Education Can Help Solve The Inequality Puzzle". www. forbes.com.

Disponible

en: $<$ http://www.forbes.com/sites/carriesheffield/2014/12/18/skills-based-education-canhelp-solve-the-inequality-puzzle/\#aa22d503fc57> [Consulta: Marzo 30, 2016].

SHUMAN, L.J., BESTERFIELD-SACRE, M. y MCGOURTY, J. (2005). "The ABET "Professional Skills" - Can They Be Taught? Can They Be Assessed?" Journal of Engineering Education, 94(1), pp.41-55. Disponible en: $<$ http://gateway.library.qut.edu.au/login?url=http://search.proquest.com/docview/217 962780? accountid=13380 \nhttp://sf5mc5tj5v.search.serialssolutions.com/?SS_Source $=3 \&$ amp;genre=article \&amp;sid=ProQ:\&amp;atitle=The

ABET \&amp;quot;Professional Skills\&amp;quot> [Consulta: Marzo 30, 2016].

SYMONDS, W.C., SCHWARTZ, R. y FERGUSON, R.F. (2011). "Pathways Prosperity Meeting the Challenge of preparing young Americans for the 21st centruty". En Pathways to Prosperity Project. Cambridge, MA.: Harward University Graduate School of Education. Disponible en: <http://nrs.harvard.edu/urn3:HUL.InstRepos:4740480> [Consulta: Marzo 30, 2016].

TREMBLAY, K., LALANCETTER, D. y ROSEVEARE, D. (2013). "OECD Assessment of Higher Education Learning Outcomes (AHELO)". En Modeling and Measuring Competencies in Higher Education. Rotterdam: SensePublishers, pp. 113-126. Disponible en: <http://link.springer.com/10.1007/978-94-6091-867-4_8> [Consulta: Marzo 30, 2016].

UPV (2016). Proyecto institucional Incorporación de las competencias transversales en el currículo de los egresados de la UPV. http://www.upv.es/. Disponible en: $<\mathrm{http} / / / \mathrm{www}$. upv.es/entidades/ICE/info/U0702452.pdf> [Consulta: Marzo 30, 2016].

(cc) EY-NC-ND 2016, Universitat Politècnica de València

Congreso In-Red (2016) 